\title{
6
}

\section{PROJECT SYRIA}

\section{Accuracy in immersive journalism}

\section{Siri Flatlandsmo and Astrid Gynnild}

This chapter investigates opportunities and dilemmas in VR journalism through a case study of Nonny de la Peña's pioneering production, Project Syria, from 2014. Project Syria exemplifies a computer-generated imagery (CGI) experience that prompts crucial journalism concerns that still await further discussion. While de la Peña and the Emblematic Group envisioned initiating an empathetic wake-up call through innovative technological means, this case study investigates in what ways and to what extent the VR story potentially deviates from established norms of accurate journalism.

This chapter zeroes in on the particular journalism challenges of using CGI in VR by applying the main principles of a well-established code-of-ethics program in journalism. Our point of departure is thus the application of the 35 bullet points provided by the American Society of Professional Journalists (SPJ), last updated in 2014.

A crucial question in this chapter is how journalists "seek truth and report it", "minimize harm", "act independently", and, at the same time, strive to "be accountable and transparent" when doing journalism based on CGI.

Moreover, it is pertinent to question to what extent a journalism code of ethics, albeit one that has been renewed regularly since 1909, can actually serve as a relevant guideline for new technologies such as VR. Does it really make sense, at present, to maintain the normative divides between journalism as a truth-seeking approach to reality and other forms of CGI? The aim of this case study is to highlight in what ways VR specifically challenges established principles of ethics in journalism. Perhaps most importantly, the goal is to reflect on how journalists maintain their journalistic integrity while experimenting with new technologies in a time of ethical flux.

Issues of what constitutes journalism are increasingly up for renegotiation and professional boundary work (Carlson \& Lewis 2020). In these cyclical rhetorical 
battles, discussants often push forward the ethical guidelines of journalism, understood as the existing global body of journalism ethics. A growing number of researchers and practitioners have voiced the need for updating and further developing journalism ethics in tandem with, in particular, the experimenting with emerging technological innovations (Bartzen Culver 2015; Johnson 2020; Kent 2015; Robitzski 2017; Ward 2019). However, few attempts have so far been made thus to implement new ethical norms in practice.

According to Raney Aronson-Rath of the PBS investigative series Frontline, which received a Knight Foundation grant to explore VR production and ethics with the Emblematic Group, "no established set of standards and ethics around applying journalism in VR environments currently exists" (Seijo 2017). As further pointed out by Deborah G. Johnson (see Chapter 7), during such a state of interpretive flexibility, many actors are engaged in pushing and pulling a new technology in different directions, and they negotiate "about the meaning of what is being developed as well as about designs and uses" (Chapter 7,p.165). Throughout history, various ethical codes sets have served as professional guidelines for what constitutes good journalism. The detailed guidelines are typically developed and taken care of by journalism organizations themselves; these guidelines vary from country to country, albeit with truth and accuracy seeming to be basic requirements. In the United States, the SPJ is dedicated to "encouraging the free practice of journalism and stimulating high standards of ethical behavior" (Spj. org 2019).

As Project Syria was created mostly in the United States by an American team, our deliberately naïve point of departure is thus the expectation that de la Peña and her crew created the piece in alignment with established ethical norms in their country. The SPJ was founded in 1909, with the mission to maintain a free press in the United States. The argument was that because "the concept of selfgovernment outlined by the U.S. Constitution remains a reality into future centuries, the American people must be well informed in order to make decisions regarding their lives, and their local and national communities" (Spj.org 2019). The SPJ is dedicated to stimulating high standards of ethical behavior in the practice of journalism. Their Code of Ethics, which journalists are expected to follow, is revised regularly, the last update having taken place in 2014.

Project Syria is an early computer-generated VR production that, in reality, represented a breakthrough for what was coined immersive journalism. De la Peña applies the term "immersive journalism" on her YouTube channel when talking about Project Syria. De la Peña claims that "[i]t's an extraordinary opportunity to be building an immersive journalism piece about Syrian children refugees. This is one of the most pressing issues of our time" (de la Peña 2014). Only two years earlier, in 2012, de la Peña and the Emblematic Group produced the first-ever walk-around VR documentary, Hunger in Los Angeles (Who We Are 2016). Project Syria, however, was specifically developed for the World Economic Forum in Davos, an event that engages societal leaders to "shape global, regional and industry agendas" (Our Mission - The World Economic Forum 2019). 
Before we dive into more details on the production, just envision going a few years back in history, before immersion became a hot topic, and imagine the following virtual jump: You are standing in your own living room, looking around at everything familiar. Then, you put on a headset packed with the latest VR technology. Suddenly, you are standing on a buzzing street in war-torn Aleppo, Syria. When you turn around, all you can see is this unfamiliar place, people you have never seen before, but you know you are there; you can hear a girl singing. Then, a bomb explodes.

There are three scenes in Project Syria. First, the viewers are put in the middle of a street in Aleppo. A girl is singing, and a bomb explodes somewhere close by. Chaos spreads. The second scene witnesses a food shortage at a food bank. In the third scene, the viewers are transported to a refugee camp in Jordan that slowly fills up with more and more tents and ghostlike refugees. Throughout the piece, a male voice is explaining the severity of the humanitarian crisis in Syria (Ekos VR Experiences 2016). In the following analysis, the 35 bullet points of the SPJ Code of Ethics are grouped in four categories: 1) Seek the truth and report it, 2) Minimize harm, 3) Act independently, and 4) Be accountable and transparent (SPJ Code of Ethics, 2014).

\section{Seek the truth and report it}

According to the SPJ Code of Ethics (2014), "[e]thical journalism should be accurate and fair. Journalists should be honest and courageous in gathering, reporting and interpreting information". However, what does it mean to be "accurate" when using VR? In one sense, the accuracy requirements imply that there is always a truth that journalism should refer to or seek to find, whereas there is less focus on perspectivizing as a chosen approach. Four years before Project Syria was born, de la Peña et al. (2010) had already pointed out that VR "can bring the reader or viewer "closer to the truth"" (293). In a VICE interview after the seminal VR production, she said it all started with a video of a girl singing in Aleppo, a video that was shown to her. As her team was concerned about authenticity, they started searching for authentic footage, which in turn served as a model for creating the virtual environment in Project Syria. On her YouTube channel, she explains how she started working with the piece after being shown the first video:

We then had to gather a dozen mobile phone videos taken before the explosion and during the aftermath, as well as photographic material and Google Earth images, to anchor the street where the event occurred. I then sent a team into a refugee camp on the border of Syria to collect material about children living in the camp in order to inform the second half of the piece. 
De la Peña and her team decided to reconstruct the photographs and videos using photographic textures and 3D models made from real people's images (de la Peña 2014). Co-producerVangelis Lympouridis explains the process in this way:

Searching with Google Translate in Arabic, we managed to find two handicam videos of the explosion and traced the location to find out exactly where and when it happened [...]. We pulled still frames from the videos, created panoramic shots, and used those to build the Aleppo neighborhood hit by the blast. For the refugee camp, we sent a team to the camp to record the situation. The audio is all real, which really creates a sense of presence.

Malmo 2014

The de la Peña solution to the accuracy dilemma corresponds to one of two generally accepted ways of building virtual worlds: "through video capture - recording a real-world scene - or by building the environment in Computer Generated Imagery" (Aronson-Rath et al. 2015, 12). When choosing the latter, however, inaccuracy is hardly possible to avoid: $2 \mathrm{D}$ images don't show everything, so the modeler has to make a decision. Just hypothesize what the backs and sides of objects look like? Or leave some things a little fuzzy to connote uncertainty? Seijo (2017) highlights the same difficulties, and poses the question of whether it is really ethical to re-enact something about which we do not have all the information (116-17). From the Code of Ethics (2014) perspective, these issues alone become problematic, as one should "[n] ever deliberately distort facts or context, including visual information", "[r]emember that neither speed nor format excuses inaccuracy", and "[c] learly label illustrations and re-enactments".

The issues of truthfulness and objectivity were a driving force in the development of cinéma vérité in the 1950s. The French documentarist Jean Rouchs attempted to find resolutions to these dilemmas by setting up a camera and letting it roll as long as the $16 \mathrm{~mm}$ film roll lasted. Cinéma vérité's attempts to document events objectively were nevertheless criticized because even by choosing where to set up the camera, the videos were, in reality, being edited. Thus, we suggest that VR (especially 360-degree video) in some ways builds a bridge back to the cinéma vérité tradition. The viewer is allowed to watch everything that is happening in front of the camera without further editing by the producers.

To avoid the ethical issues that accompany computer animation, documentarist Bryn Mooser (This Week in Startups 2015) claims that it is possible to film directly in true VR by stitching: 360-degree videos might be recorded using one 360-degree camera or by stitching together footage from several regular cameras. Mooser, who has shot several documentaries in 360, such as Welcome to Aleppo, explains that "if you put little GoPros all over the room, you could move around the environment". Making VR using videos instead of CGI would make the VR product look less like a game and more like the journalism we know. Mooser 
adds: "It's a tremendous amount of stitching" (ibid. 2015). This hints at the conflict between accuracy requirements and the fast-paced stream of news beats that journalists are expected to produce.

On the other hand, even though inaccuracy is unavoidable in VR made through CGI, is it really worse than or different from adhering to the visual documentary traditions of journalism? When a virtual environment has been artificially created, it provides the creators with large amounts of power to edit perceived reality. Just like in other kinds of journalistic storytelling, the VR journalist acts as a filter between the event and the viewer. This could be problematic if viewers perceive that they are actual eyewitnesses even when realities have already been edited. Reality is seen through the lens of a journalist, whether it is a technological one or merely a matter of perception: "The problem is that the journalist must undertake a choice of context in which to place the facts. And this choice is his own subjective choice" (Wien 2017, 5). In VR, the viewers have the freedom to choose what to focus on. However, even if the camera records everything that is visible, the viewers still cannot see what is in the street next to where the camera is set up. Deciding the location of the camera is also the journalist's choice in VR.

\section{Minimize harm by not risking safety}

According to the SPJ Code of Ethics (2014), "[e]thical journalism treats sources, subjects, colleagues and members of the public as human beings deserving of respect". As the humanitarian crises in Syria continued, it became more difficult to provide documentary video stories, and the advantages of animating virtual environments became clearer. As a VR enthusiast put it, "thanks to the rapidly growing world of virtual reality technology, there is now a way to put people outside Syria on the ground in the middle of the war without risking their safety" (Malmo 2014).

By the very nature of computer graphics, the persons depicted in Project Syria were anonymous. According to the Code of Ethics, anonymity should be reserved for sources who may face danger, and journalists should identify sources clearly, because " $[\mathrm{t}]$ he public is entitled to as much information as possible to judge the reliability and motivations of sources" (SPJ Code of Ethics 2019). However, full anonymity was not provided, as the audio was real and could still be recognized.

Anonymity which could be provided via computer graphics could be considered a good way to minimize harm because it protects the sources. With Project Syria, it could also be important to consider the safety of the people on the receiving end of the product, as they prepare for undertaking the role of eyewitnesses to traumatic events. Balancing the public's need for information against potential harm or discomfort is an important part of journalism. As pointed out by Aronson-Rath et al. (2015), "virtual reality can create feelings of 'social presence' - the feeling that a user is really 'there' - which can engender far greater empathy for the subject than in any other media representations". Because of the added feeling of presence, some viewers might find Project Syria difficult to watch. Pursuit of the news is not 
a license for arrogant or unduly intrusive behavior. At the same time, exactly what makes the video grueling to watch, according to de la Peña, is why it works well. She points out that the participant "is afforded unprecedented access to the sights and sounds, and possibly, the feelings and emotions that accompany the news" (de la Peña et al. 2010, 292).

\section{Act independently through newsgames}

The third category of the SPJ Code of Ethics (2014) guides reporters to act independently, and states that " $[\mathrm{t}]$ he highest and primary obligation of ethical journalism is to serve the public". For journalists to serve the public, the public needs to know that what they see is actually a piece of journalism. More often than not, CGI environments are associated with VR gaming, which operates far from journalism in most cases. Newsgames, by contrast, are games that "utilize the medium with the intention of participating in the public debate" (Treanor $\&$ Mateas 2009, 1). Newsgames are "not seeking to state a specific political agenda, but instead to shape the space of opinions about a current event for a group of citizens with a shared vision of public interest" (ibid., 1). Project Syria, however, nearly dictates what the viewers are supposed to feel through a male voice. This is a problem if Project Syria is considered to be journalism, but not if it is a game. Newsgames are supposed to "report and communicate about current events in a manner consistent with the theories and traditions of journalism" (Treanor \& Mateas 2009, 1). The authors suggest that newsgames serve the same role as political cartoons in a video game context.

Do these clarifications imply that a journalistic VR product can be considered a newsgame as well? Once more, it becomes apparent that clarifying the genre is of great importance. While a person looking at a political cartoon will normally be aware of the biased context, a person participating in a newsgame may not recognize the bias. If the viewers know a VR production is a game, they will most likely not expect it to present facts. If they know it is journalism, they will expect to get validated information; for journalism to serve the public, the public must be familiar with the form and genre it is presented in.

A pertinent question to raise next is whether Project Syria has more in common with a newsgame than with other journalism genres. Computer games are, as other interactive media, "different from VR in that they are not necessarily immersive" (Aronson-Rath et al. 2015). According to the founder of Oculus VR, Palmer Lucker, games are becoming more and more realistic, and have been building up to VR for a long time (CNN Business 2015). Darfur is Dying, for example, is an online game situated in a refugee camp in Sudan, in which the player uses the keyboard to avoid getting caught while fetching water for the family. This story is a newsgame meant to "increase empathy for victims of genocide by positioning the player within a game environment where the hazards refer to actual tragedy" (de la Peña et al. 2010, 293). This description fits well with Project Syria if we take into account that empathy is one of the main goals of the production. 
Project Syria was first installed at London's Victoria and Albert Museum for five days in June 2014 (Kasson 2015). Although de la Peña's work gets distributed via installations in appropriate locations, it does not have any kind of established channel where audiences can find her stories easily. With the lack of better platforms to publish Project Syria, the Emblematic Group uploaded the video to the gaming website Steam, where anyone could download it for free (Store.steampowered.com 2013). Here, one can observe what expectations do to the experience of a product. When Project Syria was uploaded to Steam, the gamers expected it to be a game.

On Steam (Store.steampowered.com 2013), users can rate and review the games. Even the users who gave the journalistic VR product a "thumbs up" rating did not like it much. A user named "kasperhviid" wrote:

The immersion doesn't kick in. Even free, this simply isn't worth it. However, the basic idea of usingVR to make a human connection to people and groups we only see described in dry news feeds is the kind of unexplored possibilities that makes me get exited [sic] aboutVR. Also, this VR experience annoyed a lot of racist nutters! For these reasons, I clicked the thumbs up - this is the kind of stuff that gives me hope for our future. But don't download - instead, imagine what this could have been.

Steam

In a similar tone, "stuttlepress" commented:

They say a VR headset can be an "empathy machine". This is an attempt toward that goal. It's a few very brief scenes documenting the humanitarian crisis in Syria. It feels like something that might be played on a loop in a kiosk as part of a larger exhibit. This is not a very polished experience. It is interesting for its aspirations more than for what it actually achieves.

Steam

These gamers gave a "thumbs up" rating and pointed out options for optimizing the video as a game. However, they do not appear to be impressed. In general, Project Syria got poor reviews on the graphics, and was also accused of being "blatant propaganda" (Store.steampowered.com 2013). Other respondents voiced that Project Syria had no reason to be on a gaming platform. This may be true, because Project Syria was not, according to de la Peña (2014), supposed to be a game.The bad reviews on the gaming platform could be more a matter of expectations attributed to the distribution platform than a reflection on the product itself.

One of Emblematic Group's goals when creating this journalistic VR product was to emphasize discussion of the humanitarian crisis among the world's most powerful people (VICE Motherboard 2014). De la Peña claims, "if we make people understand how difficult these circumstances are, perhaps they can actually start to think about what kind of change they, too, can help bring about" (de la Peña 2014). This desire to better the Syrians' circumstances places the VR production close 
to propaganda or, at best, advocacy journalism; that is, journalism that advocates a cause or expresses a viewpoint. Advocacy journalism might be an issue if the ultimate aim is to create emotion, because a journalist could be tempted to omit balancing or inconvenient information that could interfere with the desired emotional effect (Kent 2015). If empathy is the goal, the journalists must have an idea of what they want the viewers to feel.

Another aspect of "acting independently" relates to perspectivizing news events. Project Syria does not present different perspectives on the topic. The video does not accuse anyone of causing the misery we are witnessing through the headset. Project Syria is a short experience, and not many words are spoken. The most frequently used words are "children", "refugee" and "Syrians". There is no information that might explain why Syrian children become refugees, nor do we get any other verbal perspectives on the war. This lack of narration supports the impression of Project Syria as a piece of advocacy journalism or even borderline propaganda. Even though one-sided journalism is widespread on all platforms, the tendency to highlight only one side of a story is especially problematic in immersive journalism, with its strong emphasis on empathy. The founder of Oculus VR reflects on the new ethics dilemmas in this way:

It's going to be important for people to understand that just because something looks real in virtual reality does not necessarily mean it actually is real. You shouldn't assume it's real unless they are telling you, “This is unaltered, real, actual captured footage, and we haven't done anything." Without the assurance, you don't want to be falling into the trap of seeing something in VR, and because you feel like you're in the scene, saying, "This is how it actually happened."

CNN Business 2015

The blurring of VR with the real world strengthens the importance of ethics for immersive journalists. Journalists are supposed to "[d]istinguish news from advertising and shun hybrids that blur the lines between the two" (SPJ Code of Ethics, 2019). As de la Peña and her crew had a clearly expressed agenda, namely to create empathy with the Syrian refugees, it raises the question of whether the journalists serve the public or the Syrian victims only. At the same time, it should be noted that the same issues hold for other journalism genres as well, particularly the coverage of war zones or other tragic circumstances.

\section{Be accountable and transparent in the immersive world}

According to the SPJ Code of Ethics (2014), "[e]thical journalism means taking responsibility for one's work and explaining one's decisions to the public". Because the imagery in Project Syria was computer-generated, fact-checking the sources would be complicated. Despite the producers' tedious research of factual events, how is the public supposed to trust that the events in Project Syria depict what 
really happened in Aleppo? Would it be possible, in VR, for the journalists to be fully accountable and transparent in their storytelling? These are questions that are broadly discussed, but the community is still not close to any practical solutions, as $\mathrm{VR}$ and reality are increasingly merging in VR productions.

De la Peña argues that trueVR is "deep immersive", and that " $\mathrm{t}]$ he fundamental idea of immersive journalism is to allow the participant to actually enter a virtually re-created scenario representing the news story" (de la Peña et al. 2010, 292). Aronson-Rath et al. (2015) emphasize that the promise to journalists is thatVR will offer audiences greater factual understanding of a topic:

[V]irtual reality offers the promise of further breaking the "fourth wall" of journalism, wherein those represented become individuals processing agency, rather than what Liisa Malkki has referred to as "speechless emissaries".

Aronson-Rath et al. 2015

The authors argue that there are two aspects in particular that differentiate VR journalism from other kinds of conventional journalism: immersion and presence. Presence is defined as the feeling of being there, and is achieved "when one reacts to a virtual environment as he or she would to a physical world" (Aronson-Rath et al. 2015). According to Sirkkunen et al. (2016), presence "refers to the sense of being there, a state of consciousness, which has even been claimed to be the central goal of virtual reality". It is about the subjective feeling of how realistic a place is, and it is about observations of how people act similarly to how they would in a real environment. There is: 1) Place illusion, 2) The sensation of being and operating at a remote or virtual place, and 3) Plausibility (feeling that what is happening is really happening).

Aronson-Rath et al. (2015) define immersion as "the feeling that someone has left his or her immediate, physical world, and entered into a virtual environment". Two of the factors that promote immersion are the ease of interaction and how realistic the images are. Sirkkunen et al. (2016) describe immersion as "the extent to which the computer displays are capable of delivering an inclusive, extensive, surrounding and vivid illusion of reality". To rephrase the definitions in a simpler manner: Immersion is the ability to investigate the story, and presence is the feeling of actually being there.

When considering the journalistic content presented and consumed with VR technologies, the highest level of exactness is created visually by 360-degree videos. High-quality graphics can create seemingly realistic sensations visually in limited spaces. De la Peña et al. (2010) claim that in VR, people respond to what is happening in immersive virtual environments as if they were happening in our world, even when they know they are not real. The authors find it surprising that "this response-as-if-real occurs even though the level of fidelity with respect to everyday physical reality is severely reduced" (293-294). In deep interactive journalism, "the participant can feel that his or her actual location has been transformed to the location of the news story, and more importantly their actual body has 
transformed, becoming a central part of the news story itself" (de la Peña et al. 2010, 293). This kind of deep immersion makes ethics even more important, as faulty information might potentially have wide-ranging implications if the user gets confused and is convinced that certain events actually happened.

\section{Concluding remarks}

In this chapter, we have discussed reoccurring ethical challenges of using CGI in immersive journalism. Through a case study of Nonny de la Peña's pioneering VR production, Project Syria, it emerged that with new technologies, such as VR, issues of journalistic accuracy are in constant flux. No standards are currently set, and codes of ethics are only partially helpful in practice. While immersive journalism is becoming a powerful approach to engaging and influencing news audiences, the boundaries between journalism and other approaches to VR storytelling are increasingly blurred. Presence and immersion might leave viewers more vulnerable to the creators' potentially biased messages.

The analysis indicates that in Project Syria, journalistic accuracy, accountability, and transparency emerged as the most challenging dilemmas to deal with. These findings are somewhat paradoxical, as these virtues are considered particular advantages of immersive journalism.

At this point in the CGI history of immersive journalism, it is still possible for viewers to see a difference between the real world and virtual environments. Most enthusiasts agree, however, that CGI is just the beginning. When we can no longer distinguish the virtual from reality, ethical frameworks that can be adhered to will truly become imperative.

\section{References}

Aronson-Rath, Raney, James Milward, Taylor Owen, \& Fergus Pitt. 2015. "Virtual Reality Journalism." Columbia Journalism School, Tow Center. http://towcenter.org/newreport-virtual-reality-journalism [Accessed 21 January 2019].

Carlson, Matt \& Seth C. Lewis. 2020. "Boundary Work.” In: Karin Wahl-Jorgensen \& Thomas Hanitzsch (eds), The Handbook of Journalism Studies. New York: ICA/Routledge, pp. 123-135.

CNN Business. 2015. "Oculus Founder: Virtual Reality Will Change Journalism As...." YouTube video, 3:42. www.youtube.com/watch?v $=$ znmtuVN3kFE [Accessed 9 October 2015].

Culver, Kathleen B. 2015. "Immersive Approaches Pose New Questions." 11 February. Wisconsin: Center for Journalism Ethics, University of Wisconsin-Madison. https:// ethics.journalism.wisc.edu/category/virtual-reality/ [Accessed 15 March 2020].

de la Peña, Nonny. 2014. "Project Syria: An Immersive Journalism Experience." YouTube video, 4:13. www.youtube.com/watch? $\mathrm{v}=\mathrm{jN}$ _nbHnHDi4 [Accessed 28 January 2014]. de la Peña, Nonny, Peggy Weil, Joan Llobera, Elias Giannopoulos, Ausiàs Pomés, Bernhard Spaniang, Doron Friedman, Maria V. Sanchez-Vives, \& Mel Slater. 2010. "Immersive Journalism: Immersive Virtual Reality for the First-Person Experience of News." Presence: Teleoperators and Virtual Environments 19(4): 291-301. 
Ekos VR Experiences. 2016. "Project Syria - VR Recreation - Oculus Rift CV1.” YouTube video, 3:33. www.youtube.com/watch?v=digE62wpHOk [Accessed 7 November 2016].

Johnson, Deborah G. 2020. "Promises and perils of immersive journalism." In: Uskali et al. (eds), Immersive Journalism as Storytelling: Ethics, Production and Design. London: Routledge, pp. 71-81.

Kasson, Elisabeth Greenbaum. 2015. "Future Doc: Digital Storytelling,Virtual Reality and Gaming." International Documentary Association. www.documentary.org/feature/futuredoc-digital-storytelling-virtual-reality-and-gaming [Accessed 8 March 2017].

Kent, Tom. 2015. “An Ethical Reality Check for Virtual Reality Journalism.” Medium.com. https://medium.com/@tjrkent/an-ethical-reality-check-for-virtual-reality-journalism8e5230673507 [Accessed 5 April 2017].

Malmo, Christopher. 2014. "A New Virtual Reality Tool Brings the Daily Trauma of the Syrian War to Life." VI Motherboard. https://motherboard.vice.com/en_us/article/ virtual-reality-is-bringing-the-syrian-war-to-life [Accessed 4 February 2017].

Mooser, Bryn. 2015. "Bryn Mooser's RYOT.org is UsingVR to Transform Journalism \& Let Us Live Global Stories." This Week In Startups. YouTube video, 1:07:47. www.youtube. com/watch?v=WkCf6WhNQ44 [Accessed 17 September 2015].

Robitzski, Dan. 2017. "Virtual Reality and Journalistic Ethics: Where Are the Lines?" Undark.org. 27 September. https://undark.org/article/virtual-reality-and-journalisticethics-where-are-the-lines [Accessed 15 March 2020].

Seijo, Sara Pérez. 2017. "Immersive Journalism: From Audience to First-Person Experience of News.” In: Francisco Campos Freire, Xosé Rúas Araújo, Valentin Alejandro Martínez Fernández, \& Xosé López García (eds), Media and Metamedia Management: Advances in Intelligent Systems and Computing 503. Cham, Switzerland: Springer. http://link.springer. com/chapter/10.1007/978-3-319-46068-0_14 [Accessed April 25, 2017].

Sirkkunen, Esa., Heli Väätäjä, Turo Uskali, \& Parisa Pour Rezaei. 2016. "Journalism in Virtual Reality: Opportunities and Future Research Challenges." In: Academic MindTrek'16: Proceedings of the 20th International Academic MindTrek Conference. New York: Association for Computing Machinery (ACM), pp. 297-303. doi:10.1145/2994310.2994353

SPJ Code of Ethics. www.spj.org/ethicscode.asp [Accessed 14 October 2019].

Store.steampowered.com. 2013. https://store.steampowered.com/ [Accessed May 2017].

Treanor, Mike, \& Michael Mateas. 2009. "Newsgames: Procedural Rhetoric meets Political Cartoons." In: Proceedings of DiGRA 2009. www.digra.org/wp-content/uploads/digitallibrary/09300.09505.pdf [Accessed 15 March 2020].

Ward, Stephen J.A. 2019. Disrupting Journalism Ethics: Radical Change on the Frontier of Digital Media. London: Routledge.

Wien, Charlotte. 2017. "Defining Objectivity within Journalism An Overview." Nordicom Review 26(2). 